\title{
Influence of Unilateral Adrenalectomy on Renin- Angiotensin-Aldosterone System in Primary Aldosteronism
}

Terukazu Kawasakr, M.D., Keiko Uezono, M.D., Michio Ueno, M.D., Yasuhiro Noda, M.D., Kenshi Kumamoto, M.D., Yuhei Kawano, M.D., Masahiro Ogata, M.D., Koshiro Fukiyama, M.D., Teruo Omae, M.D., and Frederic C. Bartter, M.D.*

\begin{abstract}
SUMmARY
In a study of 14 patients (1 1 Japanese and 3 white North Americans) with aldosterone-producing tumor carried out within 2 to 4 weeks after unilateral adrenalectomy, both plasma renin activity (PRA) and plasma aldosterone concentration (PAG) increased almost normally with shortterm sodium depletion and upright posture. Aldosterone excretion rate (AER) also increased significantly with sodium depletion, and was normally suppressed by sodium loading. Highly significant correlations were observed between PRA and PAC $(r=0.89, p<0.001)$ or AER $(r=$ $0.88, p<0.001)$ ater operation, whereas there had been no such correlation before operation. Either physiological or laboratory findings were normalized or markedly improved in all cases although pathohistological diagnosis was made as adenomatous hyperplasia in 10 out of 11 . These results indicate that within 4 weeks of operation $\mathrm{PRA}$ and the remaining adrenal gland can almost normally respond to stimuli such as sodium depletion and upright posture regardless of the amount of spironolactone given preoperatively.
\end{abstract}

\section{Additional Indexing Words :}

Plasma renin activity Plasma aldosterone concentration Aldosterone excretion rate Spironolactone Adenoma Adenomatous hyperplasia

T MMEDIATE falls of aldosterone production were observed after removal 1 of aldosterone-producing tumors in primary aldosteronism. ${ }^{1,2)}$ Biglieri and his co-workers ${ }^{3)}$ reported that chronic hypervolemia and hypertension in primary aldosteronism could result in selective suppression of aldosterone

From the Second Department of Internal Medicine, Faculty of Medicine, Kyushu University, Fukuoka, Japan.

* ACOS for Research, the Audie Murphy Memorial Veterans Administration Hospital, Department of Medicine, University of Texas Health Science Center, San Antonio, Texas 78284, U.S.A.

Address for reprint: Terukazu Kawasaki, M.D., Second Department of Internal Medicine, Faculty of Medicine, Kyushu University, 3-1-1, Maidashi, Higashi-ku, Fukuoka 812, Japan.

Received for publication January 7, 1980. 
production immediately after removal of aldosterone-producing tumor. The juxtaglomerular apparatus is thought to be suppressed as a result of the longstanding hypervolemia and hypertension that occur secondary to elevated aldosterone production. ${ }^{4-6)}$ However, Bravo and his co-workers? have reported that the low plasma renin is not the principal cause of postoperative selective hypoaldosteronism, because patients treated with enough spironolactone preoperatively to raise PRA above normal produced inappropriately too little aldosterone for the corresponding plasma renin in the immediate postoperative period.

In our experience, however, no replacement therapy with steroid hormones was necessary after removal of aldosterone-producing tumor. Besides, in most of our cases neither contralateral nor ipsilateral adrenocortical tissue other than the adenoma or adenomatous hyperplasia showed atrophic, but rather proliferative and/or micronodular hyperplastic changes. ${ }^{11,21,81}$

The present study was made to assess whether the remaining adrenocortical tissue shortly after removal of unilateral adrenal gland bearing aldosteroneproducing tumor would be able to respond normally to various stimuli such as several manipulations of dietary sodium and postural change.

\section{Materials and Methods}

Patients: Fourteen patients with primary aldosteronism were the subjects of this study. Eleven of them ( 3 males and 8 females) were Japanese, ranging in age from 20 to 58 years (average 37.6 years) and 3 of them ( 2 males and 1 female) were white North American patients of mixed ethnic background, ranging in age from 36 to 54 years. The Japanese patients were hospitalized at Kyushu University Hospital (KUH) in Fukuoka, the white patients at the Clinical Center of the National Institutes of Health (N1H), Bethesda, Maryland. Diagnosis was based on hypertension, hypokalemia, increased plasma aldosterone concentration (PAC), and/or urinary aldosterone excretion rate(AER), suppressed plasma renin activity (PRA) and normal urinary excretion of 17-hydroxycorticosteroids (17-OHCS) and 17-ketosteroids (17-KS). A unilateral abnormality was identified on the adrenal scintiphoto scan after the administration of ${ }^{131}$ I-19-iodocholesterol, adrenal venography and measurement of bilateral adrenal vein plasma concentration of aldosterone. All had normal renal, hepatic, and cardiac function. They were found, on operation, to have aldosterone-producing tumors. All patients received spironolactone preoperatively.

Protocol: The patients were studied preoperatively under 3 different dietary conditions as follows:

1) Phase I (Control Diet): Daily dietary sodium of $194 \mathrm{mEq}$ was given for at least 5 days at KUH and of $109 \mathrm{mEq}$ for 7 days at NIH.

2) Phase II (Low-salt Diet): The patients at KUH were given a salt-poor diet ( $34 \mathrm{mEq}$ of sodium per day) for 4 to 5 days. They were given $120 \mathrm{mg}$ of furosemide orally in the morning on the first day of this span to initiate negative 
sodiun balance. The patients at NIH were given $9 \mathrm{mEq}$ of sodium per day for 4 to 6 days.

3) Phase III (High-salt Diet): The patients at KUH were given a diet containing $450 \mathrm{mEq}$ of sodium per day for a 4- to 5-day period; those at NIH were given $249 \mathrm{mEq}$ of sodium per day for a 4- to 6-day period.

Potassium intakc was maintained at 50 to $60 \mathrm{mEq}$ per day at $\mathrm{KUH}$, and at $70 \mathrm{mEq}$ per day at NIH.

On the morning following the last day of each regimen, venous blood samples were taken at 8:00 a.m., after overnight fasting and recumbency, for determination of serum electrolytes, PRA and PAC. The patients were then kept in the upright position for 1 hour at $\mathrm{KUH}$, or for 4 hours at $\mathrm{NIH}$, and blood samples were obtained again at 9:00 a.m. (KUH) or 12:00 noon (NIH).

AER or aldosterone secretion rate (ASR) was determined on the last day of each span.

The blood samples for PRA and PAC were drawn into chilled vacutainer tubes containing EDTA or heparin, respectively, and immediately centrifuged at $4^{\circ} \mathrm{C}, 3,000 \mathrm{rpm}$ for $15 \mathrm{~min}$. The plasma was separated and frozen at $-20^{\circ} \mathrm{C}$ until the determination was performed.

The same protocol was repeated 2 to 4 weeks after unilateral adrenalectomy.

Analytical methods: PRA was determined at KUH by radioimmunoassay with the kit supplied by CEA-IRE-SORIN (CIS): the method is based on a slight modification $^{9}$ of the assay system of Haber et al. ${ }^{10)}$ At NIH, PRA was measured by a modification of the method of Katz and Smith.11) PAC was measured by radioimmunoassay with the kit supplied CIS ${ }^{12)}$ at $\mathrm{KUH}$, and by the method of Kurtz and Bartter ${ }^{13)}$ at NIH. AER was measured by radioimmunoassay. ${ }^{13,14)}$ The mean \pm standard deviation (SD) of PRA and PAC were found to be $0.92 \pm 0.42 \mathrm{ng} /$ $\mathrm{ml} / \mathrm{hr}^{9)}$ and $8.2 \pm 3.2 \mathrm{ng} / 100 \mathrm{ml}^{12}$ in a recumbent position for 12 and 13 normal adults, respectively. The values of AER obtained from 6 normal males was $5.3 \pm$ $2.1 \mu \mathrm{g} /$ day reported elsewhere. ${ }^{14)}$

Serum sodium and potassium concentrations and urinary excretion of sodium and potassium were determined by flame photometry, with lithium as internal standard. All samples for a given individual were performed in the same assay. Data are presented as group mean \pm standard error of the mean (SEM). Correlations and differences were considered significant when the $\mathrm{p}$ value calculated from Student's t-test was less than 0.05 .

\section{REsults}

\section{Effects of operation on "supine" and "upright" PRA after manipulation of dietary sodium}

Pre- and postoperative PRA in supine or upright posture on 3 different sodium intakes are shown in Fig. 1. PRA was suppressed, in spite of lowsalt diet or upright posture, before operation in 10 out of 11 patients. In the remaining 1, who was reported in more detail, ${ }^{15)}$ PRA was within the normal range, and responded well to the upright posture in Phase II. When this patient was excluded, "supine" and "upright" PRA in Phase II ranged 


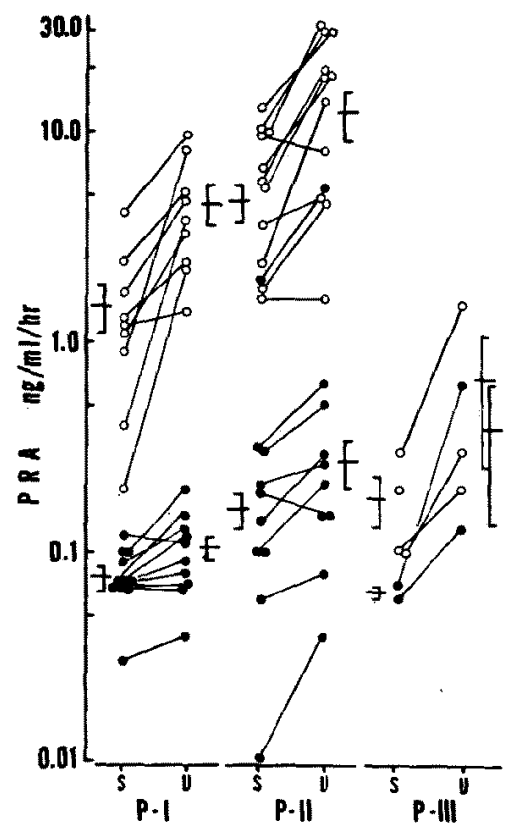

Fig. 1. Plasma renin activity (PRA) in supine (S) and upright (U) postures under 3 different dietary conditions before (closed circles) and after (open circles) unilateral adrenalectomy in Japanese patients with aldosteroneproducing tumor. P-I, P-II, and P-III represent Phase I (control diet), Phase II (low-salt diet), and Phase 1 II (high-salt diet), respectively. Each vertical bar $(t)$ represents mean \pm S.E.M.

from 0.01 to $0.31 \mathrm{ng} / \mathrm{ml} / \mathrm{hr}$ and from 0.04 to 0.65 , respectively, with average values of $0.16 \pm 0.03$ ("supinc") and $0.27 \pm 0.07$ ("upright") $\mathrm{ng} / \mathrm{ml} / \mathrm{hr}$. Within 2 to 3 weeks after operation, both "supine" and "upright" PRA in Phase I still showed subnormal values in some cases. In Phase II, however, they increased distinctly, from $1.48 \pm 0.39 \mathrm{ng} / \mathrm{ml} / \mathrm{hr}$ in Phase I to $4.63 \pm 0.94$ "supine" and from $4.54 \pm 0.93$ in Phase I to $12.24 \pm 3.24$, "upright". PRA was suppressed to $0.18 \pm 0.05$ "supine" and to $0.67 \pm 0.42$ "upright" in Phase III after operation.

Effects of operation on "supine" and "upright" PAC with manipulation of dietary sodium

Pre- and postoperative PAC in supine and upright posture on 3 different sodium intakes are shown in Fig. 2. Pre-operatively, "supine" PAC was always above normal with average values of $68.0 \pm 13.2 \mathrm{ng} / 100 \mathrm{ml}$ in Phase I, $70.9 \pm 12.2$ in Phase II, and $84.6 \pm 16.1$ in Phase III, respectively. Mean "upright" PAC under 3 different dietary conditions was always higher than the corresponding mean "supine" PAG although a statistically significant difference was observed only in Phase II $(p<0.05)$. 


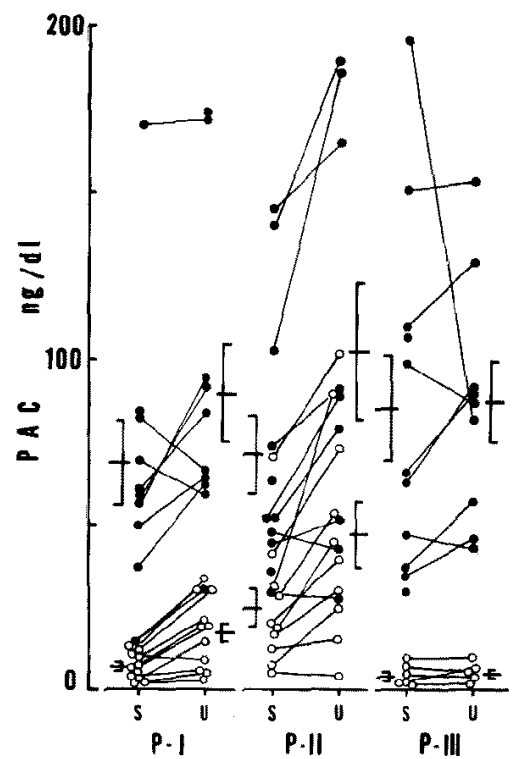

Fig. 2. Plasma aldosterone concentration (PAC) in supine (S) and upright (U) postures under 3 different dietary conditions before (closed circle) and after (open circles) unilateral adrenalectomy in Japanese patients with aldosterone-producing tumor. P-I, P-II, and P-III represent Phase I (control diet), Phase II (low-salt diet), and Phase III (high-salt diet), respectively. Each vertical bar $(€)$ represents mean \pm S.E.M.

In contrast, within 2 to 3 weeks after operation, both "supine" and "upright" PAC had fallen to subnormal values in Phase I. However, they responded well to changes in dietary sodium and posture; that is, both "supine" and "upright" PAC were significantly increased, from $6.5 \pm 1.2$ and $16.6 \pm 3.3 \mathrm{ng} / 100 \mathrm{ml}$, respectively, in Phase I to $24.7 \pm 6.2$ and $47.0 \pm 10.2 \mathrm{ng} /$ $100 \mathrm{ml}$, respectively, in Phase II ( $\mathrm{p}<0.01$ for "supine" and $\mathrm{p}<0.02$ for "upright"). Furthermore, both "supine" and "upright" PAC were significantly suppressed in Phase III, from $24.7 \pm 6.2$ to $4.4 \pm 1.4 \mathrm{ng} / 100 \mathrm{ml}$ "supine" ( $\mathrm{p}<0.01)$, and from $47.0 \pm 10.2$ to $4.8 \pm 1.3 \mathrm{ng} / 100 \mathrm{ml}$ "upright" $(\mathrm{p}<0.002)$. PAC also increased significantly with posture in Phase $\mathrm{I}(\mathrm{p}<$ $0.005)$ and in Phase II $(\mathrm{p}<0.005)$. In Phase III, however, no significant futher increment of PAC was observed in the upright posture as compared with that in the supine position; in 3 patients, there was a decrease.

Effects of operation on AER with manipulation of dietary sodium

AER, before and after operation, under 3 different dietary conditions is shown in Fig. 3. Before operation, AER was the same in Phase I, II, and III with averages of $43.5 \pm 5.9,48.6 \pm 10.9$, and $39.6 \pm 6.6 \mu \mathrm{g} /$ day, respectively. After operation, AER in Phase I had decreased remarkably to $5.4 \pm 1.6 \mu \mathrm{g} /$ day. It was significantly higher $(17.8 \pm 4.4 \mu \mathrm{g} /$ day, $\mathrm{p}<0.02)$ in Phase II, and lower 


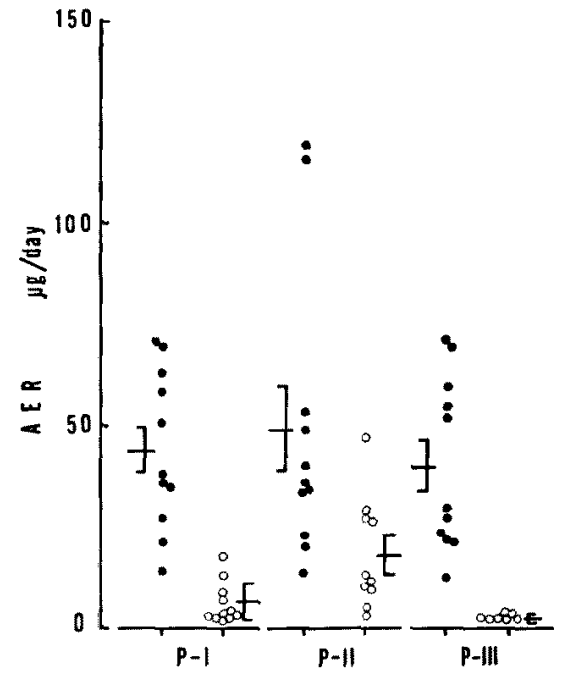

Fig. 3. Aldosterone excretion rate (AER) under 3 different dietary conditions before (closed circles) and after (open circles) unilateral adrenalectomy in Japanese patients with aldosterone-producing tumor. P-I, P-II, and P-III represent Phase I (control diet), Phase II (low-salt diet), and Phase III (highsalt diet), respectively. Each vertical bar $(t)$ represents mean \pm S.E.M.

Table I. Coefficients of Correlation among PRA, PAC, and AER in Japanese Patients with Primary Aldosteronism

\begin{tabular}{l|rrr|rrr}
\hline & \multicolumn{3}{|c|}{ Before Operation } & \multicolumn{3}{c}{ After Operation } \\
\cline { 2 - 7 } & $\mathrm{n}$ & $\mathrm{r}$ & $\mathrm{p}$ & $\mathrm{n}$ & $\mathrm{r}$ & $\mathrm{p}$ \\
\hline PRA vs. PAC & & & & & & \\
under control diet* & 20 & 0.13 & n.s. & 18 & 0.68 & $<0.01$ \\
under low-salt diet* & 17 & 0.36 & n.s. & 16 & 0.88 & $<0.001$ \\
under high-salt diet* & 4 & -0.32 & n.s. & 7 & 0.16 & n.s. \\
"Supine" PRA vs. PAC** & 22 & 0.13 & n.s. & 21 & 0.78 & $<0.001$ \\
"Upright" PRA vs. PAC** & 19 & 0.28 & n.s. & 20 & 0.93 & $<0.001$ \\
PRA vs. PAC*** & 41 & 0.17 & n.s. & 41 & 0.89 & $<0.001$ \\
"Supine" PRA vs. AER** & 23 & 0.09 & n.s. & 21 & 0.88 & $<0.001$
\end{tabular}

* regardless of posture, ** regardless of diet, *** regardless of diet and posture.

$\mathrm{n}=$ number examined; $\mathrm{r}=$ coefficient of correlation; $\mathrm{p}=$ probability of significance; n.s. $=$ not significant.

$(1.5 \pm 0.4 \mu \mathrm{g} /$ day, $\mathrm{p}<0.005)$ in Phase III.

Coefficients of correlation among $P R A, P A C$, and $A E R$ before and after operation (Table I)

There was no significant correlation between PRA and PAC or between PRA and AER before operation, as shown in Table I. After operation, however, highly significant correlations were observed between PRA and 
PAC $(r=0.89, p<0.001)$ and between PRA and AER $(r=0.88, p<0.001)$.

Effects of operation on blood pressure, serum and urinary $\mathcal{N a}$ and $K$, and urinary 17-OHCS and 17-KS in Phase I (Table II)

Blood pressure and serum $\mathrm{Na}$ fell significantly $(\mathrm{p}<0.001)$ and serum $\mathrm{K}$ rose significantly $(p<0.001)$, whereas urinary excretion of $\mathrm{Na}$ and $\mathrm{K}, 17$ OHCS and 17-KS did not change after operation.

Spironolactone administration (Table III)

Spironolactone was given to all patients in Japan at dosages ranging from 50 to $400 \mathrm{mg} /$ day, for periods ranging from 11 to 226 days, before operation. The total dose given averaged $7,300 \mathrm{mg}$, and 4 out of 11 patients received

Table II. Effects of Unilateral Adrenalectomy on Blood Pressure, Serum $\mathrm{Na}$ and $\mathrm{K}$ Concentrations, Urinary $\mathrm{Na}$ and $\mathrm{K}$ Excretions, 17-OHCS and 17-KS in Japanese Patients with Primary Aldosteronism in Phase I

\begin{tabular}{lc|c|c|c}
\hline & & $\begin{array}{c}\text { Before } \\
\text { Operation }\end{array}$ & $\begin{array}{c}\text { After } \\
\text { Operation }\end{array}$ & Significance* \\
\hline Systolic Blood Pressure & $(\mathrm{mmHg})$ & $186 \pm 10.6$ & $120 \pm 4.3$ & $\mathrm{p}<0.001$ \\
Diastolic Blood Pressure & $(\mathrm{mmHg})$ & $104 \pm 2.4$ & $73 \pm 2.3$ & $\mathrm{p}<0.001$ \\
Serum Na Concentration & $(\mathrm{mEq} / \mathrm{L})$ & $144.3 \pm 0.8$ & $139.2 \pm 0.6$ & $\mathrm{p}<0.001$ \\
Serum K Concentration & $(\mathrm{mEq} / \mathrm{L})$ & $2.98 \pm 0.14$ & $4.87 \pm 0.15$ & $\mathrm{p}<0.001$ \\
Urinary Na Excretion & $(\mathrm{mEq} /$ day $)$ & $118.0 \pm 11.1$ & $103.5 \pm 12.1$ & $\mathrm{n.s.}$ \\
Urinary K Excretion & $(\mathrm{mEq} /$ day) & $39.5 \pm 2.2$ & $46.6 \pm 5.3$ & n.s. \\
Urinary 17-OHCS & $(\mathrm{mg} /$ day) & $6.16 \pm 0.57$ & $5.37 \pm 0.53$ & n.s. \\
Urinary 17-KS & $(\mathrm{mg} /$ day $)$ & $6.64 \pm 0.83$ & $5.58 \pm 0.86$ & n.s.
\end{tabular}

* significant difference between before and after operation. n.s. = not significant.

Table III. Doses and Periods of Spironolactone Treatment in Patients with Primary Aldosteronism

\begin{tabular}{rrr|r|r|r}
\hline \multicolumn{2}{c|}{ Patients } & $\begin{array}{c}\text { Period } \\
\text { (days) }\end{array}$ & $\begin{array}{c}\text { Average dose } \\
\text { (mg/day) }\end{array}$ & $\begin{array}{c}\text { Total dose } \\
\text { (mg) }\end{array}$ \\
\hline 1. & 40 & $\mathrm{M}$ & 11 & 150 & 1,650 \\
2. & 43 & $\mathrm{M}$ & 365 & 4,000 \\
3. & 52 & $\mathrm{M}$ & 11 & 60 & 12,650 \\
4. & 20 & $\mathrm{~F}$ & 226 & 4,950 \\
5. & 22 & $\mathrm{~F}$ & 33 & 310 & 10,500 \\
6. & 31 & $\mathrm{~F}$ & 34 & 4,450 \\
7. & 33 & $\mathrm{~F}$ & 17 & 260 & 3,900 \\
8. & 34 & $\mathrm{~F}$ & 14 & 190 & 8,950 \\
9. & 40 & $\mathrm{~F}$ & 47 & 180 & 3,300 \\
10. & 41 & $\mathrm{~F}$ & 18 & 210 & 12,200 \\
11. & 58 & $\mathrm{~F}$ & 58 & 275 & 14,000
\end{tabular}


Table IV. Pre- and Post-Operative Study of Renin-Angiotensin-Aldosterone System in 3 White North American Patients with Primary Aldosteronism

\begin{tabular}{|c|c|c|c|c|c|c|c|c|c|c|}
\hline \multirow{2}{*}{\multicolumn{2}{|c|}{ Patients }} & \multicolumn{3}{|c|}{ Control Diet } & \multicolumn{3}{|c|}{ Low-salt Diet } & \multicolumn{3}{|c|}{ High-salt Diet } \\
\hline & & $\begin{array}{l}\text { S/U- } \\
\text { PRA }\end{array}$ & $\begin{array}{l}\text { S/U- } \\
\text { PAC }\end{array}$ & AER & $\begin{array}{l}\text { S/U- } \\
\text { PRA }\end{array}$ & $\begin{array}{l}\mathrm{S} / \mathrm{U}- \\
\mathrm{PAC}\end{array}$ & AER & $\begin{array}{l}\text { S/U- } \\
\text { PRA }\end{array}$ & $\begin{array}{l}\text { S/U } \\
\text { PAC }\end{array}$ & AER \\
\hline \multirow[t]{2}{*}{$54, F$} & Pre & 一 & - & - & $1.8 / 1.7$ & - & $1,000^{*}$ & $2.4 /-$ & - & $734^{*}$ \\
\hline & Post & $1.3 / 1.9$ & - & $196^{*}$ & - & - & - & - & - & - \\
\hline \multirow[t]{2}{*}{$36, F$} & Pre & $0.0 / 0.4$ & $87 / 74$ & - & $2.1 / 1.2$ & $216 / 121$ & 143 & $0.3 / 0.5$ & $86 / 41$ & 93 \\
\hline & Post & $2.1 / 4.9$ & - & 8.2 & $6.2 / 16.2$ & $26 / 127$ & 22.3 & $1.3 / 1.9$ & $6.4 / 13.7$ & 5.6 \\
\hline \multirow[t]{2}{*}{$46, \mathrm{M}$} & Pre & $2.1 / 1.3$ & $57 / 17$ & 34.2 & $0.7 / 0.8$ & $70 / 29$ & 35.9 & $0.9 / 0.5$ & $58 / 19$ & 33.4 \\
\hline & Post & $1.9 / 2.0$ & $5.2 / 12$ & 4.7 & $3.2 / 12.1$ & $21 / 56$ & 20.5 & $0.1 / 0.3$ & $2.5 / 3.1$ & 2.6 \\
\hline
\end{tabular}

Pre= before operation ; Post =after operation; S/UPRA="supine" and "upright" plasma renin activity (ng/ml/hr); S/U-PAC= "supine" and "upright" plasma aldosterone concentration (ng/ $100 \mathrm{ml}) ; \mathrm{AER}=$ aldosterone excretion rate $(\mu \mathrm{g} / 24 \mathrm{hr}) . \quad *$ aldosterone secretion rate $(\mu \mathrm{g} / 24 \mathrm{hr})$.

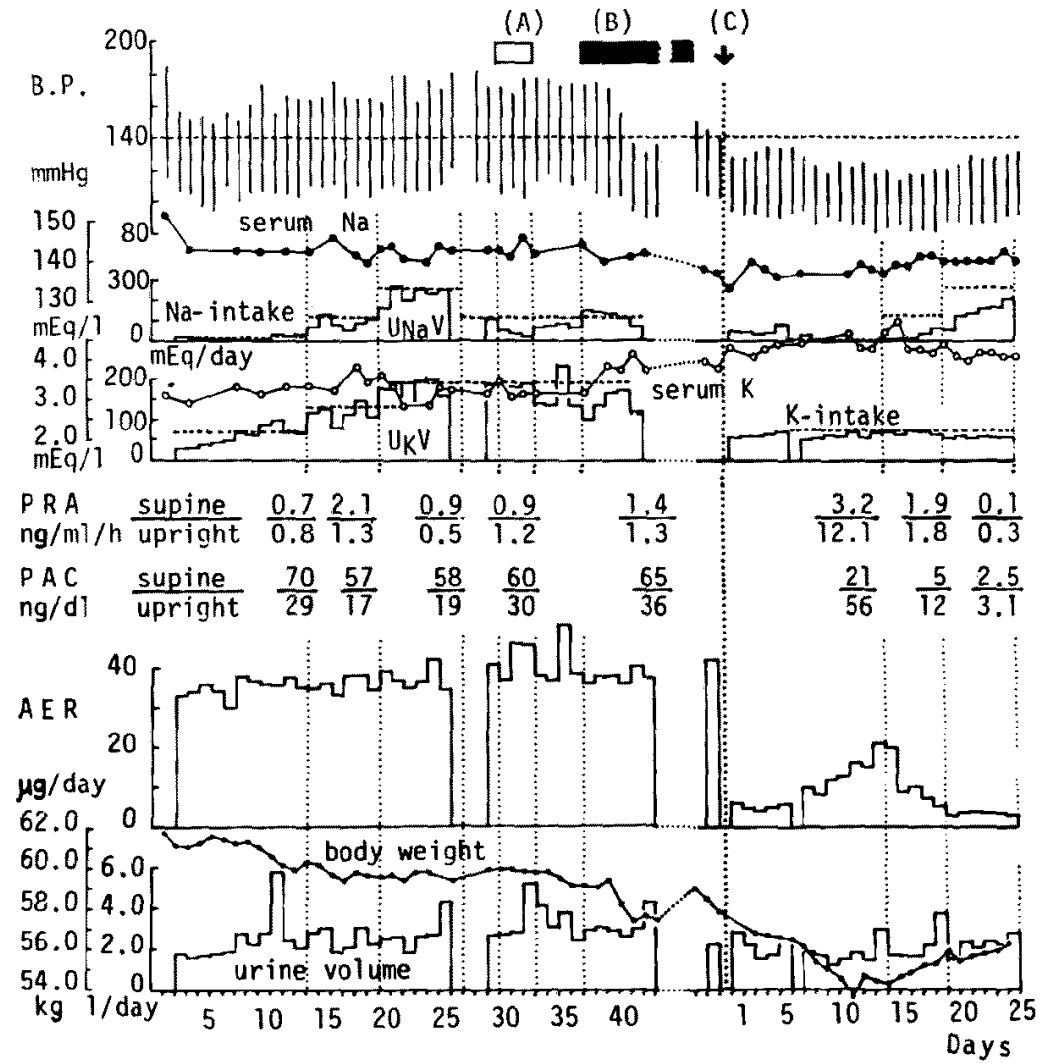

Fig. 4. Balance study in NIH. J.B.C. 46 y.o. male, primary aldosteronism.

(A): Desoxycorticosterone acetate (DOCA) $10 \mathrm{mg}$, b.i.d. for 3 days.

(B): Spironolactone $100 \mathrm{mg}$, q.i.d. for 5 months.

(C): Left unilateral total adrenalectomy.

Abbreviations: B.P. $=$ blood pressure; $P R A=$ plasma renin activity; $P A C=$ plasma aldosterone concentration; $\mathrm{AER}=$ aldosterone excretion rate; $\mathrm{UNaV}=$ urinary excretion of sodium; UKV = urinary excretion of potassium. 
more than $10,000 \mathrm{mg}$. Spironolactone was not given to any patients after operation.

Pre- and postoperative study of the renin-angiotensin-aldosterone system in 3 white patients with primary aldosteronism in the United States

Data are shown in Table IV. Complete studies were performed on 2 out of 3 patients, whose responses to dietary sodium manipulation following operation were quite similar to those of the Japanese patients; They were given 200 and $400 \mathrm{mg} / \mathrm{day}$ of spironolactone for 6 and 5 months (total: 36,000 and $63,000 \mathrm{mg}$ ) before a unilateral adrenalectomy was done. The remaining 1 also received a large amount of spironolactone for more than 6 months. An entire metabolic balance study at the Clinical Center of NIH is illustrated in Fig. 4 .

\section{Histopathological findings}

Table $\mathrm{V}$ lists the histopathological findings at operation. In no case did the ipsilateral adrenal tissue surrounding the tumor show "atrophy" on microscopic examination.

Table V. Histological Findings

\begin{tabular}{c|c|l|ll}
\hline Patients & $\begin{array}{c}\text { Size of tumor } \\
(\mathrm{mm})\end{array}$ & Location & \multicolumn{2}{|c}{ Pathological findings } \\
\hline 1. & $20 \times 16 \times 14$ & Right & AHP & MNHP \\
\hline 2. & $15 \times$ & Left & AHP & small nodules \\
3. & $13 \times 13 \times 10$ & Right & AHP & MNHP \\
4. & $16 \times 13 \times 8$ & Right & AHP & no atrophy \\
5. & $15 \times 14 \times 12$ & Left & AHP & no atrophy \\
6. & $25 \times 20 \times 18$ & Left & AHP & MNHP \\
7. & $16 \times 16 \times 12$ & Left & AHP & MNHP, hyperplastic \\
8. & $8 \times 8 \times 5$ & Right & AHP & MNHP \\
9. & $20 \times 17 \times 14$ & Left & A & hyperplastic \\
10. & $14 \times 14 \times 11$ & Left & AHP & MNHP \\
11. & $22 \times 1$ & Right & AHP & MNHP \\
\end{tabular}

$\mathrm{AHP}=$ adenomatous hyperplasia $; \mathrm{A}=$ cortical adenoma $; \mathrm{MNHP}=$ micronodular hyperplasia.

\section{Discussion}

When an adenoma was difined as a benign tumor being completely encapsulated, it was found in only 1 case as shown in Table V. In the remaining 10 cases, pathohistological diagnosis was made as adenomatous hyperplasia. The finding was in accord with our previous experience. ${ }^{1,2)}$ Neither clinical features nor histological findings except for the continuity of a capsule 
of a tumor ${ }^{2)}$ showed essential differences between the cases with adenoma and adenomatous hyperplasia. Therefore, our patients are not different from those with aldosterone-producing adenoma described by others. ${ }^{31,71,16 \text { ) }}$

It was reported that restoration of aldosterone production did not observe for at least 1 month after removal of aldosterone-producing tumor. ${ }^{3), 7), 16 \text { ) }}$ Biglieri and his coworkers ${ }^{31}$ suggested that long-term suppression of renin secretion by hypervolemia and hypertension was thought to account for the subnormal production of aldosterone by the remaining adrenal gland. In most of our cases, however, both PRA and aldosterone responded normally to sodium depletion and to the upright posture within 2 to 4 weeks after operation. Again, hormonal replacement therapy such as fludrocortisone or corticosterone administration was not required not only in our patients investigated here or previously reported ${ }^{1,2), 8}$ but also in many others. ${ }^{17)-20)}$ The histopathological findings in our patients did not suggest depression of aldosterone secreting capacity, since there was no suggestion of atrophy either on the same side as the tumor, or contralaterally. ${ }^{1,2), 81}$ Similar histological findings were observed by others. ${ }^{17-22)}$ Tsuchiyama ${ }^{23 /}$ has emphasized the contribution of zona glomerulosa of nontumorous area to the excess of aldosterone production in patients with primary aldosteronism in terms of morphological and histochemical standpoints. Contralateral adrenal gland seems to be able to respond well to various stimuli to increase aldosterone production.

Morimoto and his co-workers ${ }^{16)}$ found that large doses of spironolactone ( 300 to $400 \mathrm{mg} /$ day) for 2 months or more before operation prevented the nonresponsiveness of PRA to appropriate stimuli following removal of aldosterone-producing tumor, whereas low levels of AER were observed within at least 1 month after operation. After preoperative treatment with small or moderate doses of spironolactone for periods as short as 11 days or as long as 1 year, all our patients could respond almost normally to sodium depletion and to the upright posture with increases in PRA, PAC, and AER withi 22 to 4 weeks after operation although only 4 patients received more than 10,000 mg of spironolactone as shown in Table III. Three cases in NIH also revealed almost normal values in PRA and aldosterone postoperatively and responded well to the sodium depletion or to the upright posture despite taking a large amount of spironolactone preoperatively. These results are inconsistent with those of other investigators. ${ }^{7), 16)}$

Bravo and his co-workers ${ }^{\text {i) }}$ showed that postoperative unresponsiveness of aldosterone secretion occurred even after prolonged use of spironolactone preoperatively at dosages sufficient to raise PRA to supernormal values for prolonged intervals. They considered that such suppression could account 
for the failure of their patients to produce aldosterone postoperatively despite supernormal values for PRA and suggested that spironolactone itself inhibited the adrenal cortex since there had been considerable experimental evidences that spironolactone could suppress the biosynthesis of aldosterone. ${ }^{24-27)}$ In the present study, however, highly significant correlation between PRA and PAC or AER was observed within 1 month following removal of aldosterone-producing tumor. Even if inhibiting aldosterone biosynthesis occurred in our patients, it must have been short-lived. ${ }^{28}$

These evidences support our conclusion that the juxtaglomerular apparatus and the contralateral adrenal gland might respond almost normally to the upright posture or sodium deprivation within 1 month following removal of an aldosterone producing tumor regardless of the amount of spironolactone given preoperatively.

\section{ACKNOWLEDGMents}

We wish to thank Mrs. Sumiko Nakamuta, Misses Tomoko Koike and Reiko Katsuya for their excellent technical assistance.

\section{REFERENCES}

1. Kawasaki T: A study of patho-physiological features of "primary aldosteronism ". Fukuoka Acta med 61 : 82, 1970 (in Japanese with English abstract)

2. Omae T, Kawasaki T, Tanaka K, Arakawa K, Emoto K, Masaki Z, Katsuki S: Hyperaldosteronism due to adrenocortical adenoma and adenomatous hyperplasia. Endocrinol Japon 18: 57,1971

3. Biglieri EG, Slaton PE Jr, Silen WS, Galante M, Forsham PH: Postoperative studies of adrenal function in primary aldosteronism. J Clin Endocrinol Metab 26: 553, 1966

4. Biglieri EG, Forsham PH: Studies on the expanded extracellular fluid and the responses to various stimuli in primary aldosteronism. Am $\mathrm{J}$ Med 30: 564, 1961

5. Rovner DR, Conn JW, Knoff RF, Cohen EL: Nature of renal escape from the sodiumretaining effect of aldosterone in primary aldosteronism and in normal subjects. J Clin Endocrinol Metab 25: 53, 1965

6. Conn JW, Rovner DR, Cohen EL: Normal and altered function of the renin-angiotensinaldosterone system in man. Applications in clinical and research medicine. Ann Intern Med 63: 266, 1965

7. Bravo EL, Dustan HP, Tarazi RC: Selective hypoaldosteronism despite prolonged pre- and postoperative hyperreninemia in primary aldosteronism. J Clin Endocrinol Metab 41: 611, 1975

8. Kawasaki T, Omae $\mathrm{T}$, Tanaka K, Matsunaga M, Emoto K: Remission of recurrent hyperaldosteronism resulting from sub-total adrenalectomy of adenomatous hyperplastic adrenal glands. J Clin Endocrinol Metab 33: 474, 1971

9. Kumamoto K: Effects of acute sodium depletion on blood pressure and renin-angiotensinaldosterone system in patients with benign essential hypertension. Fukuoka Acta Medica 68: 397, 1977. (in Japanese with English abstract)

10. Haber E, Koerner T, Page LB, Kliman B, Purnode A: Application of radioimmunoassay 
for angiotensin $I$ to the physiologic measurement of plasma renin activity in normal human subjects. J Clin Endocrinol Metab 29: 1349, 1969

11. Katz FH, Smith JA: Radioimmunoassay of angiotensin I. Comparison of two renin activity methods and use for other measurements of the renin system. Clin Chem 18: 528, 1972

12. Nakamuta $\mathrm{S}, \mathrm{K}$ umamoto $\mathrm{K}$, Kawasaki $\mathrm{T}$, Omae $\mathrm{T}$ : Measurement of plasma aldosterone concentration by radioimmunoassay kit (ALDOK). Clin Pathol 24: 163, 1976 (in Japanese)

13. Kurtz AB, Bartter FC: Radioimmunoassay for aldosterone and desoxycorticosterone. Steroids 28: 133,1976

14. Nakamuta $\mathrm{S}$, Kawasaki T, Kumamoto $\mathrm{K}$, Omae $\mathrm{T}$ : Basic study for the measurement of urinary aldosterone excretion rate by radioimmunoassay. Clinics and Research 54: 2236, 1977 (in Japanese)

15. Kumamoto K, Ueno M, Kawasaki T, Noda $Y$, Fukiyama K, Omae T: A case of primary aldosteronism without suppressed renin. Jpn Circulat J 42: 109, 1978 (in Japanese)

16. Morimoto S, Takeda $\mathrm{R}$, Murakami $\mathrm{M}$ : Does prolonged pretreatment with large doses of spironolactone hasten a recovery from juxtaglomerular-adrenal suppression in primary aldosteronism? J Clin Endocrinol Metab 31: 659, 1970

17. Neville AM, Symington T: Pathology of primary aldosteronism. Cancer 19: 1854, 1966

18. Priestly JT, Ferris DO, ReMine WH, Woolner LB: Primary aldosteronism. Surgical management and pathological findings. Mayo Clin Proc 43: 761, 1968

19. George JM, Wright L, Bell NH, Bartter FC: The syndrome of primary aldosteronism. Am J Med 48: 343,1970

20. Ferriss JB, Beevers DG, Boddy K, Brown JJ, Davies DL, Fraser R, Kremer D, Lever AF, Robertson JIS: The treatment of low-renin ("primary") hyperaldosteronism. Am Heart J $96: 97,1978$

21. Brode E, Grant JK, Symington T: A biochemical and pathological investigation of adrenal tissues from patients with Conn's syndrome. Acta Endocrinol 41: 411, 1962

22. Ferriss JB, Beevers DG, Brown JJ, Davies DL, Lever AF, Mason P, Neville AM, Robertson JIS: Clinical, biochemical and pathological features of low-renin (" primary") hyperaldosteronism, Am Heart J 95: 375, 1978

23. Tsuchiyama $\mathrm{H}$ : Morphological studies of human adrenal cortex under pathologic conditions. Acta Pathol Jap 17: 155, 1967

24. Erbler HC: Stimulation of aldosterone production in vitro and its inhibition by spironolactone. Naunyn-Schmiedeberg's Arch Pharmacol 273: 366, 1972

25. Erbler HC: On the mechanism of the inhibitory action of spironolactone SC9376 (Aldadiene) on the production of corticosteroids in rat adrenals in vitro. Naunyn-Schmiedeberg's Arch Pharmacol 277: 139, 1973

26. Sundsfjord JA, Marton P, Jorgensen H, Aakvaag A: Reduced aldosterone secretion during spironolactone treatment in primary aldosteronism. Report of a case. J Clin Endocrinol Metab 39: 734, 1974

27. Erbler HC: The effect of saluretics and spironolactone on aldosterone production and electrolyte excretion in man. Naunyn-Schmiedeberg's Arch Parmacol 286: 145, 1974

28. Gaillard RC, Riondel AM, Chabert P, Vallotton MB: Effect of spironolactone on aldosterone regulation in man. Clin Sci 58:227, 1980 